\title{
Oportunidades para la cocreación de contenidos en los diarios nativos digitales
}

\section{Opportunities for content co-creation in digital native newspapers}

\author{
José Sixto-García; Xosé López-García; Carlos Toural-Bran
}

Cómo citar este artículo:

Sixto-García, José; López-García, Xosé; Toural-Bran, Carlos (2020). “Oportunidades para la cocreación de contenidos en los diarios nativos digitales". Profesional de la información, v. 29, n. 4, e290426.

https://doi.org/10.3145/epi.2020.jul.26

Artículo recibido el 16-10-2019

Aceptación definitiva: 06-02-2020

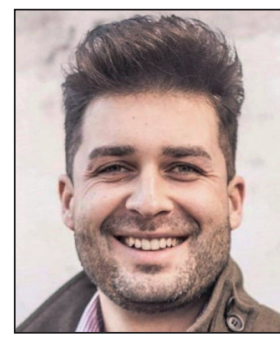

José Sixto-García $\square$

https://orcid.org/0000-0002-2988-0975

Universidad de Santiago de Compostela Facultad de Ciencias de la Comunicación Avenida de Castelao, $\mathrm{s} / \mathrm{n}$.

15702 Santiago de Compostela

(A Coruña), España

jose.sixto@usc.es

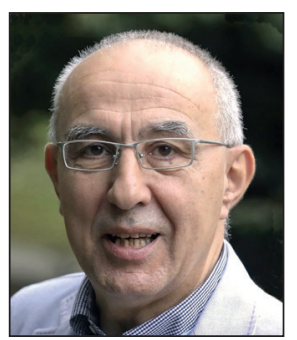

Xosé López-García

https://orcid.org/0000-0002-1873-8260

Universidad de Santiago de Compostela

Facultad de Ciencias de la Comunicación

Avenida de Castelao, s/n. 15702

Santiago de Compostela

(A Coruña), España

xose.lopez.garcia@usc.es

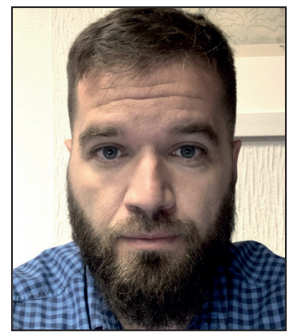
Carlos Toural-Bran
Avenida de Castelao, $\mathrm{s} / \mathrm{n}$.
15702 Santiago de Compostela
(A Coruña), España
carlos.toural@usc.es

https://orcid.org/0000-0002-0961-3925

Universidad de Santiago de Compostela

Facultad de Ciencias de la Comunicación

\section{Resumen}

La participación de los usuarios en la creación de productos informativos aumenta el valor de los medios de comunicación e incrementa la satisfacción de los cocreadores. La involucración de los lectores afecta en especial a los procesos productivos, aunque sin desmerecer la implicación en el desarrollo y en el marketing, e implica democratización de la información, experiencias personalizadas y puntos de vista diversos que favorecen el pluralismo informativo. En esta investigación se analiza una muestra internacional compuesta por cinco diarios nativos digitales para comprobar en qué medida permiten a sus públicos cocrear contenidos. Se utiliza una metodología exploratoria para comprobar la existencia de espacios concebidos para la cocreación. Se confeccionan unas escalas de evaluación del grado de utilidad de la idoneidad de esos sitios y se examina su accesibilidad desde la perspectiva del empoderamiento ciudadano, la apertura de contenidos y la arquitectura web. Los resultados demuestran que los grados de implantación alcanzados por los diarios son más bajos de lo que pudiera esperarse de medios puramente digitales y alertan sobre la necesidad de idear nuevas fórmulas de cocreación e implicar más a las audiencias en la generación de contenidos, al tiempo que se hace necesario revisar con profundidad cuál es su papel como fuentes. Las limitaciones al empoderamiento ciudadano derivadas de la ausencia de publicidad en los modelos de negocio restringen los accesos en abierto y las jerarquías web obstaculizan las colaboraciones. Se diagnostica, asimismo, la necesidad de que los ciudadanos puedan identificar con claridad qué productos han sido elaborados por periodistas y cuáles por cocreadores.

Este artículo está elaborado en el marco del proyecto “Cibermedios nativos digitales en España: formatos narrativos y estrategia móvil (RTI2018-093346-B-C33)”, del Ministerio de Ciencia, Innovación y Universidades, cofinanciado por el Fondo Europeo de Desarrollo Regional (Feder). 


\title{
Palabras clave
}

Diarios nativos digitales; Periodismo digital; Prensa digital; Cocreación; Valor; Participación; User generated content; Prosumers; Adprosumers; Empoderamiento ciudadano; Audiencias; Arquitectura web; Accesibilidad; Fuentes.

\begin{abstract}
The participation of readers in the creation of information products increases the value of the media and the satisfaction of co-creators. Such involvement of the public especially affects productive processes, although without ignoring their participation in development and marketing, and implies a democratization of information, personalized experiences, and diverse points of view that favor informative pluralism. In this research we analyze an international sample of five digital native newspapers to verify the extent to which they allow their audiences to co-create content. We use an exploratory methodology to verify the existence of spaces designed for co-creation and prepare evaluation scales for the level of utility of these sites and examine their accessibility from the perspective of citizen empowerment, openness of content, and web architecture. The results show that the degree of implementation achieved by newspapers is lower than may be expected for purely digital media and provide a warning about the need to devise new formulas for co-creation and involve audiences more in generating content, while also indicating the need to review in depth the role of readers as sources. The limitations on citizen empowerment that derive from the absence of advertising in business models restrict open access, while web hierarchies hamper collaboration. The need for citizens to clearly identify which products have been produced by journalists versus co-creators is also diagnosed.
\end{abstract}

\section{Keywords}

Digital native newspapers; Digital journalism; Digital press: Co-creation; Value; Participation; User-generated content; Prosumers; Adprosumers; Citizen empowerment; Audiences; Web architecture; Accessibility; Sources.

\section{Introducción}

La consolidación de la sociedad red (Castells, 1996), el rol activo de las audiencias y la creación de redes colaborativas (Masip; Suau, 2014) en un ecosistema comunicativo caracterizado por medios híbridos (Chadwick, 2013) han alimentado nuevas dimensiones en las estrategias de producción informativa de los cibermedios nativos digitales, nacidos y pensados para el escenario digital que camina de la mano de internet. La digitalización ha impulsado numerosos cambios periodísticos en el campo de la producción, que van desde la producción multimedia (Deuze, 2004; George-Palilonis, 2012) hasta los blogs (Singer, 2005), el contenido generado por los usuarios y la participación de la audiencia (Carpentier, 2011; Singer et al., 2011; Holton; Lewis, Coddington, 2016); el crowdsourcing y el periodismo de datos (Anderson, 2013; Bruns, 2016), los medios sociales, el periodismo móvil (Westlund, 2013), la personalización de información y de servicios (Thurman, 2011), transmedia (Scolari, 2009; Rampazzo; Peret, 2016) o la realidad virtual (De-la-Peña et al., 2010) y los debates éticos que suscita (Kool, 2016), por citar alguno de los más relevantes.

Los medios de comunicación, en especial los nativos digitales, adquieren un compromiso cada vez mayor de involucrar a los públicos en la configuración de los productos que ofrecen. Las suscripciones y los ingresos por publicidad en muchos casos ya no resultan suficientes para mantener un medio solvente, por lo que la agregación de contenidos está ganando terreno día a día, de modo que también se espera que los productos que realizan los lectores acaben en las búsquedas web (Bakker, 2012). La democratización de la participación ciudadana y de la creatividad en los procesos productivos no es una tendencia exclusiva de los medios, sino que existe una corriente generalizada en todo tipo de organizaciones (Kotler, 2018) que apuesta por que los productos son más valiosos (Prahalad; Ramaswamy, 2004; Ostrom et al., 2010) si los consumidores participan en su confección. En realidad, el concepto de valor está detrás de cualquier fórmula de cocreación, pues hemos pasado de una visión centrada en el producto y en la empresa a la personalización de experiencias de compra y consumo que aportan valor al usuario. Atrás ha quedado ya la fórmula clásica del marketing en que los consumidores no formaban parte de la organización, sino que ambos tenían roles distintos de producción y consumo, respectivamente (Kotler, 2002; Porter, 2004). Las organizaciones han interiorizando que las interacciones sociales de alta calidad que permiten a los usuarios el desarrollo de experiencias únicas e individualizadas sustentadas en la cocreación constituyen la gran ventaja competitiva de cara al horizonte 2020-2030.

No solo la industria de medios, sino muchos otros sectores se están enfocando hacia un modelo de negocio donde la ideación, el diseño y la producción de servicios y contenidos se confía a la colaboración entre productores y consumidores (Malmelin; Villi, 2015), de forma que cada vez se desdibuja más la línea entre quien produce y quien consume (Örnebring, 2008). En efecto, un requisito imprescindible para la aparición de las redes multiplataforma fue la arquitectura de los productos digitales, que permitió nuevas formas de diseñar, producir, distribuir y usar la tecnología (Yoo; Henfridsson; Lyytinen, 2010). De todos modos, la creación de valor no es una competencia exclusiva del consumidor, sino que en esa configuración ha de participar indisolublemente el binomio usuario-medio/empresa. Muchas compañías pretenden crear valor aprovechando las posibilidades de contacto con los usuarios y las

Hemos pasado de una visión centrada en el producto y en la empresa a la personalización de experiencias que aportan valor al usuario 
sinergias creadas en las comunidades (Kaplan; Haenlein, 2010), pero sólo con eso no basta. La cocreación va más allá de situar al usuario en el centro de los procesos productivos o comunicativos, de ofrecerle experiencias preparadas de antemano o de filtrar la información en función de sus hábitos de consumo, lo que únicamente contribuye a un deterioro del pluralismo informativo

(Aalberg; Blekesaune; Elvestad, 2013; Sunstein, 2017), y se fundamenta, en cambio, en permitir a los públicos coconstruir su propia experiencia en su propio contexto, ayudándose mutuamente en la resolución de problemas y fomentando espacios participativos que permitan experiencias personalizadas, pero también diferentes para cada uno de los usuarios que decide participar en ellos (Prahalad; Ramaswamy, 2004; Aitamurto, 2013).

El éxito de los modelos de periodismo ciudadano en los contextos digitales supone un cambio sustancial en la relación entre los productores de información y las audiencias. El concepto produsage explica la lógica de la producción entre iguales porque difumina los límites entre el consumo pasivo y activo (Bruns, 2010). La producción se interpreta como una experiencia en la creación conjunta de textos (Pavlíčková; Kleut, 2016) o productos, aunque la teoría del produsage deba concebirse más como una práctica social que como un proceso de producción de noticias (Picone, 2011).

\section{Exigencias para la cocreación}

\subsection{Usuarios empoderados}

Sólo los consumidores informados, conectados y empoderados son capaces de articular prácticas de cocreación. Como han demostrado varios estudios previos (Gruner; Homburg, 2000; Fiore et al., 2005; Wang et al., 2007; Kim et al., 2009; Roser et al., 2009; Malthouse; Hofacker, 2010; Malmelin; Villi, 2015), es la tecnología lo que ha permitido y favorecido la expansión de plataformas y servicios digitales que posibilitan la interacción entre todo tipo de empresas y sus stakeholders, pero ahora les toca a los medios y a las organizaciones en general desarrollar mecanismos de detección de sus posibles colaboradores externos para poder involucrarlos en los procesos comunicativos y creativos.

Frow, Payne y Storbacka (2015) conciben el empleo de las estrategias de cocreación como un diseño que parte de los motivos empresariales que justifican el empleo de este tipo de prácticas para la consecución de los objetivos primarios y secundarios. Ello pasa por la constitución de las plataformas necesarias para poner en marcha la interacción entre la organización y los agentes colaborativos, y que remata con la determinación del grado de involucramiento que se les concederá a los públicos. Así pues, los autores identifican diversas formas de cocreación como la coconcepción de ideas, el codiseño, la coproducción, la copromoción, el coprecio, la codistribución, la coconsumición, el comantenimiento, el cooutsourcing, la codisposición, la coexperiencia o la cocreación de significado.

En la actualidad el concepto de empoderamiento se aplica a tantos y tan diferentes tipos de situaciones y grupos sociales y tipos de intervención, que difícilmente podemos concluir que para que se dé el efecto de empoderamiento el punto de partida debe ser el de una situación de desventaja económica. Es decir, el concepto tiende a aplicarse de manera generosa y amplia en el sentido que también le daba la RAE en la edición de 2005 de su Diccionario panhispánico de dudas, de

"conceder poder [a un colectivo desfavorecido socioeconómicamente] para que, mediante su autogestión, mejore sus condiciones de vida".

En cualquier caso, el poder para el que se empodera es entendido como una propiedad dinámica susceptible de crecer o disminuir, por lo que, junto con la investigación centrada en el empoderamiento de grupos e individuos en diferentes ámbitos, encontramos también resultados de trabajos que describen efectos de "desempoderamiento" en la sociedad de la información (Mariën; Prodnik, 2014; Fuente-Cobo, 2016).

En esta entrega de poder a los usuarios para que realicen cambios, aporten datos o determinen el significado y la concepción última de un producto la bibliografía diferencia cuatro niveles de empoderamiento (Piller; Ihl; Vossen, 2010) que adaptamos al escenario específico del periodismo digital:

(1) empoderamiento nulo u orientación al producto en que no se permite a los usuarios interactuar en el proceso de desarrollo en ningún nivel, sino que el medio produce y el mercado consume;

(2) empoderamiento selectivo o delegación pequeña de poder a las audiencias para decidir sobre ideas desarrolladas previamente por el medio;

(3) empoderamiento creativo, caracterizado por dar libertad a los consumidores para opinar y crear aquello que consideren más adecuado para sus intereses particulares, aunque supeditado a la decisión final del medio; y

(4) empoderamiento total o involucramiento total de los públicos para aceptar el proceso de cocreación sin ningún tipo de restricciones y permitir el lanzamiento de productos informativos que los usuarios consideran que satisfarán sus necesidades. 
Cuando el empoderamiento es total, la concepción de los públicos como prosumers resulta limitada y obsoleta, puesto que los usuarios no sólo consumen y producen contenido interpretativo o de opinión para redes u otros espacios sociales 2.0, sino que también prescriben y viralizan las experiencias positivas que, en muchos casos, ellos mismos han creado. Se convierten, así, en adprosumers que participan activamente en la definición y en el desarrollo de productos y que actúan como portavoces de la marca (Segarra-Saavedra; Tur-Viñes, 2017), incluso captando entre sus redes de contactos a nuevos prosumers para el producto o a nuevos adprosumers para la marca o el medio. Por tanto, las prácticas de cocreación no suelen producirse en grupos heterogéneos o masivos, sino en comunidades más pequeñas compuestas por audiencias segmentadas (Villi, 2012) en las que el consumo de la marca actúa como adherente para conectar a unos consumidores con otros (Fournier; Avery, 2011).

Adprosumers y prosumers suelen crear user generated content (ugc), que siempre aportan valor (Carvalho, 2014), aunque suelen estar más predispuestos a hacerlo para los entornos sociales que para los medios de comunicación en sí (Zhang; Sarvary, 2015). Shao (2009) identificó que los usuarios generan este tipo de contenido motivados por su autosatisfacción y para tener un espacio donde expresar y actualizar los datos que conocen, mientras que Ahn, Duan y Mela (2016) concluyeron que las expectativas de los usuarios con respecto a la cantidad y el momento en que otros participan les resultan determinantes para su propia participación. Es conveniente, pues, que las áreas

Los espacios para la generación de contenidos no pueden limitarse a las redes sociales, sino que deben habilitarse espacios propios para la generación de este tipo de contenidos no se limiten a plataformas externas como las redes sociales o los blogs, sino que dentro de los propios espacios corporativos existan entornos o mecanismos que permitan la incubación de ideas para la cocreación y la elaboración de contenidos o que, al menos, estén habilitados para trasladar datos de refuerzo que puedan usar los editores para seleccionar los temas y los periodistas para elaborar las informaciones.

No queremos decir con esto que cualquier ciudadano pueda convertirse en periodista, pero sí que ante la imposibilidad de tener un informador en todos los lugares, los profesionales puedan contextualizar o reforzar su relato con pruebas, fotografías, vídeos o datos que los públicos pueden remitirles gracias a los mecanismos que facilita la tecnología. A veces, como señaló Holmes (2004), una simple votación online puede influenciar y determinar la configuración del temario de un medio. $\mathrm{O}$, por poner otro ejemplo, un vídeo sobre un incendio remitido por un telespectador puede añadir el valor del momento preciso a la pieza informativa que se pueda elaborar en la redacción. Es por ello que la curación de contenidos se hace más indispensable que nunca para el periodismo del siglo XXI, que convive en paralelo con un contexto de volumen y caos informativo en la red (Guallar; Codina, 2018).

\subsection{Una industria mediática que permita cocrear}

La potestad para permitir el empoderamiento de las audiencias y facilitar los procedimientos de consumo, valoración, recomendación y, en definitiva, de creación de productos reside exclusivamente en el medio digital. El medio no puede limitarse a idear y diseñar espacios para la cocreación, sino que, además, ha de asegurar que se implementan de manera correcta para que tengan éxito. Para determinar ese entorno que favorece la innovación y, por tanto, la cocreación, Prahalad y Ramaswamy (2004) recomiendan:

a) priorizar los objetivos empresariales a largo plazo frente a los más cortoplacistas,

b) garantizar la accesibilidad y la transparencia de las webs,

c) favorecer la inclusión de grupos heterogéneos de cocreadores para contribuir a la diversidad de ideas,

d) promover la cocreación a través de canales múltiples y, al mismo tiempo,

e) comprender que no todos los consumidores -ni siquiera los más activos-, quieren cocrear, por lo que se deben evitar presiones y evaluar los niveles de satisfacción de los usuarios.

Los autores citados entienden que una implementación efectiva de espacios cocreativos se sustenta en cuatro pilares que constituyen el modelo DART (diálogo, acceso, riesgo y transparencia):

- El diálogo debe concebirse para interpretar la óptica de los usuarios y permitirles cocrear la experiencia o el producto que más se ajuste a sus necesidades. A esta perspectiva externa se ha de sumar también la interna, es decir, la de los periodistas y trabajadores del medio para asegurar su compromiso con la innovación y la convivencia con otros colaboradores externos que tienen poder de decisión sobre el producto final.

- Sin facilitar el acceso no es posible que las audiencias se conviertan en creadoras, por lo que es necesario proporcionarles la mayor cantidad de aplicaciones y plataformas para implicarlas en los procesos. A ello añadimos que se deben garantizar las condiciones de accesibilidad de esos servicios para que posibiliten materializar la colaboración.

- Los usuarios también tienen derecho a conocer los riesgos que implica colaborar y cocrear, lo que exige sistemas informativos eficaces y actualizados que les permitan elegir en qué medio participar y evaluar las ventajas y los inconvenientes que eso les supone.

- La transparencia entre medio y stakeholders es una condición indispensable para avalar los resultados óptimos de la cocreación y aumentar los índices de confianza entre ambos, lo que faculta consolidar un marketing de relaciones alejado de intercambios o colaboraciones esporádicas. 
El poder que entregan las empresas informativas a los usuarios en las prácticas actuales de cocreación transciende la coproducción (Bendapudi; Leone, 2013; Frow; Payne; Storbacka, 2015), que la bibliografía concibe como una primera etapa de la cocreación en que las colaboraciones con agentes externos se limitaban sólo a un ámbito de la producción sin posibilidad de cocrear en áreas diferentes de la organización. Si entendiéramos la cocreación como la suma de codiseño (ideación) + coproducción (desarrollo), estaríamos excluyendo igualmente otras áreas organizacionales vinculadas al marketing o a la atención al usuario, y más en especial en el caso de los adprosumers que concentran gran parte de su activismo en recomendar productos y prescribir marcas. Cuando el consumidor tradicional se convierte en adprosumer aumenta el nivel de engagement con la marca (Brodie et al., 2011; Hollebeek, 2013) porque el usuario se compromete tanto que llega a pensar que forma parte de ella, que le aporta valor (Potts et al., 2008) e, incluso, que su propiedad le pertenece (Aitamurto, 2013).

Así pues, la cocreación debe concebirse como un proceso interactivo, creativo y social entre los grupos de interés de la organización, que ella misma inicia y que se produce en los diferentes niveles del proceso de creación de valor, lo que implica la apertura de la empresa hacia terceros y la voluntad de esos terceros de involucrarse (Ind; Coates, 2013; Roser; DeFillippi; Samson, 2013; Agrawal; Kaushik; Rahman, 2015). Cocrear supera la innovación abierta, ya que aglutina las estrategias para innovar aprovechando las relaciones con los públicos externos (Chesbrough, 2006; Teece, 2007; Aylen, 2010) y con la búsqueda permanente del valor. Por tanto, aunque pueda parecer que existe cierta similitud en la concepción de los usuarios en los modelos de cocreación y crowdsourcing, Aitamurto (2013) los emplea como recursos intelectuales, pero no los empodera en ningún caso, tal y como recogemos en la siguiente tabla:

Tabla 1. Diferencias entre cocreación y crowdsourcing

\begin{tabular}{|l|l|l|}
\hline \multicolumn{1}{|c|}{ Cocreación } & \multicolumn{1}{c|}{ Característica } & \multicolumn{1}{c|}{ Crowdsourcing } \\
\hline Usuarios o usuarios potenciales & Externalización dirigida a... & Grupo amplio de personas \\
\hline Segmentado & Tipo de público & Generalista \\
\hline Empoderamiento & Concepción usuarios & Recursos intelectuales sin empoderamiento \\
\hline Crear productos de valor + beneficios económicos & Objetivos de la organización & Experiencia, conocimiento + producto final \\
\hline Crear y consumir productos de valor & Objetivos de los stakeholders & Personales y/o económicos \\
\hline
\end{tabular}

El empoderamiento ciudadano provoca que las necesidades intrínsecas de los públicos tengan más posibilidades de satisfacerse (Kotler, 1991; Yi, 1990) mediante actividades creativas y, en consecuencia, a través de sus contribuciones creativas los cocreadores podrían alcanzar mayores beneficios psicológicos que los que obtendrían si sólo consumiesen sin participar (OHern; Rindfleisch, 2015), una tendencia de la que investigadores como Firat, Dholakia y Venkatesh (1995) ya alertaron a finales del siglo XX.

\subsection{Aprovechar el conocimiento}

Los cambios en las relaciones entre quien consume y quien produce afectan a la manera que tiene el medio de explotar el conocimiento del usuario para aprovecharlo en la cocreación de contenidos (Sawhney; Prandelli, 2000) y, a la vez, la tecnología provoca que las opciones personalizadas sean cada vez más accesibles para los públicos (Graham, 2015). De hecho, uno de los grandes desafíos de la industria de medios actual radica en seguir creando redes creativas en que los contenidos sean cocreados por las audiencias, los usuarios, los partners o las subcontrataciones (Malmelin; Villi, 2015).

Los primeros estudios sobre cocreación en medios (Hartley, 2004; Comor, 2010) pronosticaron un avance en las interacciones sociales con los públicos. Sin embargo, a pesar de intentar poner en marcha una cultura más participativa, la mayoría de las prácticas informativas seguían ejerciendo un modelo unidireccional y se mantenían reticentes a dejar en manos de las audiencias las fases de producción o edición de los contenidos, por lo que limitaban la participación a la distribución multiplataforma (Karlsson, 2011; Bruns, 2012; Jenkins; Carpentier, 2013; Küng, 2016), en especial en las redes sociales (Napoli, 2010). Otras investigaciones previas (Wardle; Williams, 2010; Hermida, 2011) constataron que los medios recurrían a los lectores para que les facilitasen materiales que pudiesen derivar en noticias como fotografías o relatos de historias.

Aitamurto (2013) analizó el éxito de los procesos de cocreación en la revista finlandesa Olivia, una publicación consolidada orientada a un target femenino, y confirmó que lectoras y periodistas aunaban esfuerzos en la búsqueda de historias. Halló un proceso de cocreación estructurado que considera cada relato como un desafío en todas las fases de la producción periodística. Ultima, no obstante, que las intenciones de los lectores confrontan con los objetivos de la revista y que los editores perciben esos deseos como una amenaza a la filosofía empresarial que acaba generando tensiones. Además, se detecta que la cocreación añade complejidad a la producción informativa y que el medio considera que los productos cocreados exigen un tiempo de elaboración mayor que los tradicionales.

Al estudiar el valor de las noticias en la era social, Graham (2015) llegó a la conclusión de que el propósito final de la industria mediática no era solo empezar a definir los nuevos nichos de mercado de esta nueva era social, sino asegurarse de que se podían crear y sostener cadenas de valor con ellos viables financieramente, pero también alertó de que a medida que mejora la participación del consumidor en los procesos de creación, producción y distribución de noticias se conduce a crear nuevas oportunidades y a disminuir los costes de las transacciones y los riesgos de producción. Ya un año antes Picard (2014) había puesto de manifiesto que los proveedores de noticias eran cada vez menos dependientes 
de cualquier forma de financiación y auguraba un nuevo modelo cuya sostenibilidad dependía de servicios comerciales relacionados con el alojamiento web, los servicios de publicidad en internet, las relaciones entre lectores y anunciantes, el comercio electrónico, las fundaciones y los patrocinadores. Franklin (2014) percibió que la era de los medios digitales es testigo de la innovación y el cambio radical en todos los aspectos del periodismo, lo que, por una parte, crea dificultades económicas para los medios que tienen que transformase y, por otra, un torbellino de ideas para buscar modelos de negocio alternativos para financiar un periodismo sostenible en el futuro.

Malmelin y Villi (2015) propusieron un marco de referencia para analizar los modelos de cocreación existentes en los medios sustentado en tres aspectos fundamentales:

- el desarrollo (ideación + renovación),

- la producción (planificación + ejecución), y

- el marketing (promoción + distribución).

Acotaron su investigación a dos revistas finlandesas, Demi y Lily, y concluyeron que en ambos casos las comunidades de usuarios se implicaban en la producción de contenidos y en el mantenimiento de conexiones interpersonales hasta el punto de que los procesos cocreativos tenían un impacto definitivo en el trabajo diario: el equipo editorial mejoraba y editaba los ugc para publicar, seguía las propuestas y las sugerencias de temas de las comunidades de usuarios o, entre otras acciones, se preparó un prototipo de web para que lo testase un grupo de usuarios, de modo que se comprobó que las comunidades de usuarios contribuían activamente a desarrollar y renovar la marca.

\section{Objetivos y metodología}

El objetivo principal de esta investigación es comprobar la existencia de espacios destinados a la cocreación en los diarios nativos digitales. Establecemos cuatro objetivos secundarios:

01: Analizar las fórmulas para la cocreación de contenidos.

O2: Identificar los espacios para cocrear en función de los tipos de acceso a los contenidos (en abierto, bajo registro o reservados para socios) y, en consecuencia, el nivel de empoderamiento de los públicos.

O3: Examinar el tipo de consumidor que tiene acceso a los productos cocreados por otros.

O4: Evaluar la accesibilidad a los espacios corporativos en la arquitectura de las webs corporativas.

Para ello hemos seleccionado una muestra internacional de cinco cabeceras de referencia, todas ellas justificadas por tratarse de modelos singulares en su país y por la fuerza con que entraron en el escenario digital en su conjunto: De correspondent (Holanda), elDiario.es (España), Mediapart (Francia), Observador (Portugal) y Politico (Estados Unidos). Se trata, pues, de una muestra de carácter intencional, una técnica de muestreo no probabilístico que se utiliza en escenarios donde la población es variable y consiguientemente la muestra muy pequeña, por lo que permite seleccionar casos característicos de ese universo (López-Roldán; Fachelli, 2015; Otzen; Manterola, 2017).

Empleamos un método exploratorio fundamentado en un barrido de datos, lo que nos permitió identificar pautas y comportamientos que van más allá de una instantánea efímera de la situación. Catalogamos todos los elementos de modalidad participativa en las webs de los diarios y medimos las dimensiones de desempeño de las prácticas destinadas a la cocreación en ese universo. El estudio se centra en los espacios corporativos que son propiedad del medio y, por tanto, susceptibles de adaptación y modificación por parte del grupo editorial, de modo que se descartan otros sitios externos más vinculados a prácticas cross-media como las redes sociales donde se da por descontada la participación de los usuarios y donde la capacidad de actuación del medio es más limitada.

Basándonos en el modelo de las escalas de Likert, que evita las respuestas dicotómicas y permite conocer el grado de conformidad del entrevistado con las propuestas presentadas (Wigley, 2013), hemos diseñado un instrumento para evaluar el valor de utilidad de los espacios destinados a la cocreación. Para ello, también hemos tomado como referencia las rúbricas que comúnmente se utilizan en las Ciencias de la Educación para la evaluación de las competencias adquiridas por los estudiantes mediante guías de puntuación (Cano, 2015) y las hemos adaptado como instrumento evaluativo a la investigación en Periodismo. Distinguimos cinco grados $-A, B, C, D$ y E- (donde A es el más alto y E el mínimo) a los que hemos adjudicado una puntuación de 5, 4, 3, 2 y 1 punto, respectivamente. Luego, hemos diseñado una escala específica para cada objetivo que se plantea en la investigación.

En primer lugar, con respecto al análisis de las fórmulas destinadas a la cocreación (objetivo 1) y sólo en este caso, los niveles no son excluyentes, sino sumativos, pues es precisamente la complementación lo que determina la excelencia en los procesos cocreativos (hasta 15 puntos, correspondientes a la suma de los 5 items):

\begin{tabular}{|l|l|}
\hline A & Espacio participativo para la cocreación de contenidos \\
\hline B & Involucración del lector como fuente de valor en la investigación periodística \\
\hline C & Propuestas de corrección de textos, ugc y/o filtraciones confidenciales \\
\hline D & Repercusión de las interacciones sociales en los contenidos informativos \\
\hline E & Diálogo social a partir de contenidos creados por el medio \\
\hline
\end{tabular}


Con respecto a los tipos de acceso a los espacios concebidos para la cocreación (objetivo 2), distinguimos tres grados de empoderamiento en función de si el acceso es libre o si exige pago. Las dimensiones D y E no se recogen porque implican inexistencia de sitios para cocrear y se aplica un índice de corrección de -2 puntos en el caso de las participaciones en comunidades sociales que exigen moderación o aprobación previa del equipo editorial:

\begin{tabular}{|l|l|}
\hline A & Cocreación abierta a cualquier usuario \\
\hline B & Cocreación reservada a usuarios registrados \\
\hline C & Cocreación reservada a socios \\
\hline
\end{tabular}

En relación con el tercer objetivo planteado, evaluamos las posibilidades de acceso de los lectores a los productos que otros han cocreado y también distinguimos tres dimensiones:

\begin{tabular}{|l|l|}
\hline A & Lectura en abierto de productos cocreados \\
\hline B & Lectura de productos cocreados reservada a usuarios registrados \\
\hline C & Lectura de productos cocreados reservada a socios \\
\hline
\end{tabular}

Por último y en relación con el objetivo 4, no sólo es destacable que los medios ofrezcan a los usuarios espacios participativos, sino que esos lugares les resulten fácilmente accesibles para poder conocerlos y valorar una posible participación. Por tanto, diferenciamos cinco grados de accesibilidad de la arquitectura web de los sitios corporativos:

\begin{tabular}{|l|l|}
\hline A & Sin scroll y con un solo clic \\
\hline B & Sin scroll y con dos clics \\
\hline C & Con scroll y con un clic \\
\hline D & Con scroll y con dos clics \\
\hline E & Con scroll y con más de dos clics \\
\hline
\end{tabular}

Un medio que alcanzase un grado de utilidad A en todos los apartados alcanzaría la puntuación máxima de 30 puntos, equivalente a que el grado de implantación de cocreación en el medio estaría plenamente conseguido. Establecemos una escala para la evaluación global de resultados (tabla 2).

Tabla 2. escala para la evaluación global de resultados

\begin{tabular}{|c|c|}
\hline Puntuación conseguida & Grado de implantación de la cocreación \\
\hline Entre 30 y 27 puntos & Total \\
\hline Entre 26 y 20 puntos & Alto \\
\hline Entre 19 y 15 puntos & Medio \\
\hline Entre 14 y 10 puntos & Bajo \\
\hline Menos de 10 puntos & Inapreciable \\
\hline
\end{tabular}

\section{Cocreación en diarios nativos digitales}

\subsection{De correspondent (Holanda)}

Después de una exitosa campaña de crowdfunding en la primavera de 2013 en que 18.333 personas apostaron por un medio que todavía no existía, el 30 de septiembre de ese mismo año nacía De correspondent, cuya misión es involucrar activamente a todos sus socios en el periodismo, y que hoy en día cuenta con más de 62.000 abonados, de quienes depende su viabilidad económica, ya que no alberga ningún tipo de publicidad. No obstante, según figura en su Manifest, están abiertos a colaboraciones con otros medios y también aceptan financiación de organizaciones que no comprometan una independencia editorial completa. Eso provoca que los usuarios que no están suscritos no puedan acceder a los contenidos, salvo a una pequeña muestra que identifican como cortesía de un socio concreto ("Este artículo es su regalo hecho por el miembro que paga Rosan Smits", por ejemplo).

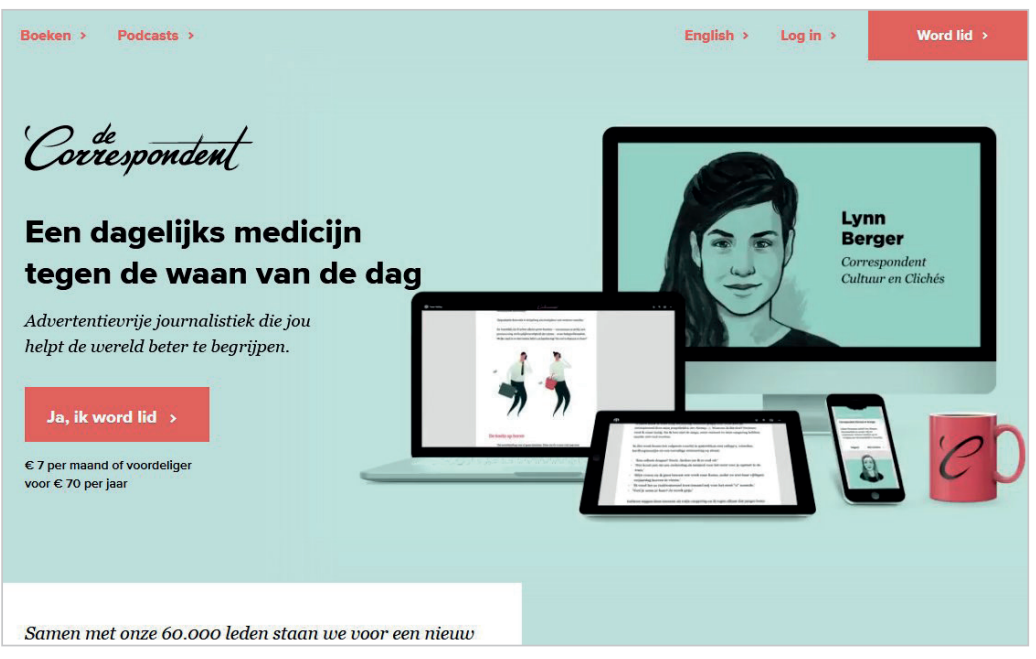

https://decorrespondent.nl 
De correspondent se nutre de una red de periodistas, los llamados corresponsales, que comparten un objetivo común, esto es, comprender los que consideran los temas más importantes de la sociedad actual como el cambio climático, el envejecimiento de la población o la salud. Para ello les resulta imprescindible la colaboración con socios que sean expertos en esas materias y, de hecho, conciben a los lectores como fuentes que aportan valor. Las corresponsalías tienen libertad absoluta para configurar las agendas periodísticas y los temarios a cambio de dotarse de una "personalidad apasionada" que despierte interés en los socios, por lo que se les exige que elijan asuntos que proporcionen información sobre el desarrollo estructural y global, que cambien la idea de neutralidad informativa por un enfoque abierto y crítico, que consideren a los lectores como fuentes de conocimiento, que los involucren en la investigación periodística, que mantengan un cuaderno público para proporcionar información sobre el trabajo documental realizado y que conciban el storytelling como una forma de contar historias de forma clara, accesible, conmovedora y rigurosa. El propio cibermedio engloba estas rutinas productivas en lo que denominan periodismo constructivo, caracterizado no sólo por contar los hechos, sino por aportar soluciones a los problemas que se presentan en los relatos.

El digital promete integrar al corresponsal en un equipo editorial que valora las ideas y que prima la colaboración frente a la jerarquía, pues entiende que los socios saben más sobre la mayoría de los temas que ellos mismos, lo que provoca que su relación con los públicos no se limite a proporcionarles información, sino también a recibirla, de modo que el lector abandona su rol de consumidor pasivo de noticias y se convierte en un experto que aporta un conocimiento de valor para las historias. Para conseguir este propósito hacen públicas las preguntas de investigación y las hipótesis de las que emanan las informaciones, siempre bajo la premisa de que es más importante la calidad que la cantidad y de que la objetividad no existe. Apuestan, pues, por la interpretación de los hechos frente a la neutralidad o la imparcialidad, así como por la transparencia y la contextualización en los puntos de vista, lo que exige una búsqueda activa de periodistas y socios con perspectivas y antecedentes de vida diversos, también en una apuesta clara por las políticas de inclusión.

Los usuarios que están registrados, pero no son socios, reciben una newsletter los sábados por la mañana con una relación de temas que están publicados en la web y cuya lectura sólo es accesible para los asociados. En efecto, los suscriptores tienen acceso ilimitado a todo el contenido, pueden hablar y hacer preguntas a los corresponsales, compartir la información publicada y explorar el archivo digital, compuesto por más de 6.000 artículos.

El periódico ofrece la posibilidad de que los usuarios cocreen ellos mismos relatos o informaciones o bien que le faciliten ese material a un corresponsal para que lo difunda a cambio de una contraprestación económica. Cuando un lector decide cocrear debe cubrir un formulario para plantear la formulación de la investigación, determinar el enfoque y decidir el target al que se dirigirá el producto. Luego, se le convoca a una entrevista telefónica en un plazo máximo de tres semanas. La aceptación del tema se supedita a las siguientes condiciones:

- Debe implicar un diálogo con la comunidad de socios.

- Ha de centrarse en un desarrollo a largo plazo, es decir, que no sea relevante sólo en una fecha determinada, sino que se trate de un asunto atemporal.

- El usuario debe exponer por qué le parece interesante el tema y exponer su punto de vista al respecto.

- La información debe emanar de una experiencia propia o implicar la participación del usuario.

- Las noticias han de sustentarse en investigaciones exhaustivas y estar avaladas por fuentes fiables y contrastadas.

- El tema no puede limitarse a exponer el problema, sino que debe proponer soluciones posibles.

- Ha de tratarse de un asunto original que implique una percepción distinta de la actualidad y que no se pueda encontrar en otros medios de comunicación.

- La historia debe romper estereotipos, refutar prejuicios y disipar mitos.

Las cocreaciones en De correspondent se pagan en función de un acuerdo entre el equipo editorial y el autor. La interacción con los socios se especifica como una parte indispensable del trabajo y la remuneración, de modo que se evita que el producto sea una pieza separada y se convierta en el comienzo de una conversación entre los integrantes de la comunidad. La propiedad del trabajo pertenece siempre al autor, aunque el medio se reserva el derecho de difundirlo en otras plataformas vinculadas.

\section{2. elDiario.es (España)}

En el elDiario.es se diferencian tres niveles para la cocreación: las fórmulas concebidas para los usuarios registrados, las específicas para socios y la alternativa para los que ni se registran ni se asocian, pero que desean enviar al medio una filtración o una información altamente confidencial.

Los usuarios registrados disponen de un espacio propio, un perfil, que permite la identificación con nombre real o nick y que puede asociarse a un avatar. En ese perfil queda constancia de la actividad de participación en la web, de tal forma que los comentarios se recopilan junto a las interacciones sociales que han generado. Los usuarios registrados mediante email o vínculo con las redes sociales pueden corregir los textos publicados por el medio a través de la aplicación 'he visto un error', que posibilita reportar errores ortográficos o gramaticales y datos incorrectos. En caso de que al lector no le satisfaga esta opción, existe otra vía, 'elDiario.es responde', en que el director, Ignacio Escolar, contesta cada domingo en un blog a las sugerencias enviadas desde el departamento de socios. Se trata de una alternativa a las cartas al director -que el medio critica por falta de feedback- y una apuesta por la transparencia en las políticas de gestión económica. 
En la app los usuarios registrados tienen la opción de personalizar su propia portada con los temas, las secciones y los autores que siguen.

elDiario.es dedica parte de su arquitectura web a un objetivo empresarial prioritario: la conversión de los lectores en socios. Argumentan su propósito en dos premisas fundamentales: una política de transparencia que muestra que más del 33\% de los ingresos proceden de los abonos de sus 34.000 socios y la necesidad de contar con una prensa libre e independiente ajena a intereses políticos y económicos que actúe como un verdadero cuarto poder. Bajo el lema "Sin ti, este periodismo independiente no es posible", elDiario.es ofrece siete servicios exclusivos para sus asociados, de los que tres $(5,6$ y 7$)$ están directamente relacionados con la cocreación de contenidos:

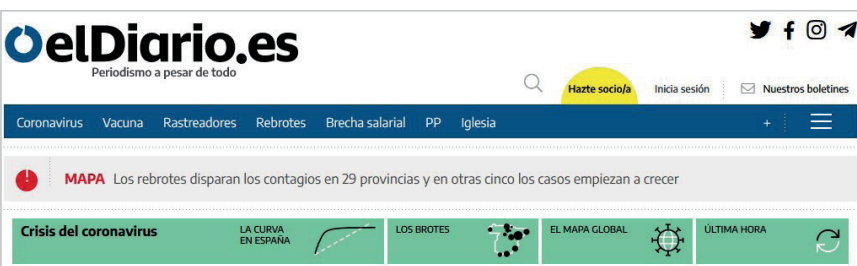

Sanidad registra 2.789 nuevos casos de coronavirus y Madrid es ya la segunda comunidad con más nuevos contagios

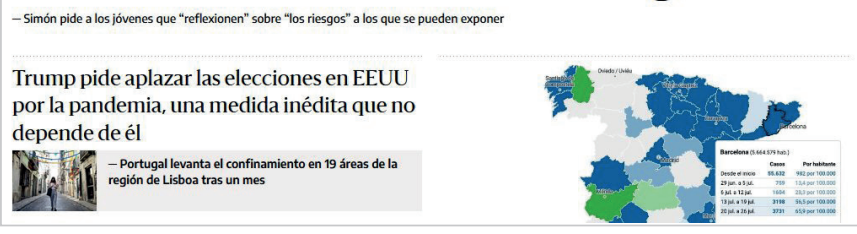

https://www.eldiario.es

- Recepción de revistas monográficas con periodicidad trimestral (los boletines están accesibles también para registrados).

- Eliminación de publicidad tanto en la web como en la app.

- Emisión de descuentos y promociones, así como posibilidad de rellenar formularios para participar en sorteos de entradas para actividades culturales.

- Adelanto diario de las noticias que se publicarán a la mañana siguiente.

- Los comentarios de los socios aparecen destacados e identificados como tal y, además, son tenidos en cuenta por la redacción. Por otra parte, el diario ofrece a sus asociados una aplicación para denunciar los comentarios que incumplan las normas de la comunidad ('moderar comentario'), la opción de votar y la funcionalidad de 'silenciar usuarios', aunque también penalizan los abusos de poder. Se trata de que la comunidad sea autónoma en la gestión de las interacciones sociales y, en efecto, aconsejan resaltar las opiniones más valiosas, respetuosas y constructivas.

- Encuentros específicos para socios en los que es posible debatir con los periodistas del medio.

- Votaciones online.

De todas formas, Escolar reconoce que estas no son las mejores opciones para proporcionar pistas que puedan llevarles a destapar una información, por lo que para estos casos facilitan una dirección de correo electrónico (pistas@eldiario. es) que asegura el anonimato del remitente de acuerdo con el código deontológico, mientras que para la filtración de documentos oficiales o confidenciales proponen filtrala.org, una plataforma de referencia para filtraciones seguras que garantiza el anonimato de la fuente incluso para el medio. Se trata de una plataforma de envío que funciona gracias al software de código libre GlobaLeaks, desarrollado por Hermes Center for Transparency and Digital Human Rights, que garantiza que ni siquiera el propio sistema de envíos pueda obtener datos de rastreo sobre la identidad o la ubicación del emisor. Para ello hacen especial hincapié en el uso de un navegador específico, Tor, que permite explorar la red a través de un sistema cifrado y sin hacer visible la dirección IP. Precisamente, la misión del medio apuesta por dar voz a la ciudadanía en un contexto que el equipo editorial caracteriza como dotado de una oferta informativa cada vez menos plural, lo que les a lleva a enfocar la política y la economía en el sentido que afecta a las personas, más que a los partidos o a los mercados.

El aviso legal de la web contempla la existencia de espacios dedicados a la participación y a fomentar la conversación entre los usuarios y matiza que todos los user generated content (fotografías, imágenes con o sin movimiento, textos, informaciones, bases de datos, grabaciones sonoras o cualesquiera otras obras o prestaciones) se ceden de manera gratuita, sin carácter de exclusiva, así como los derechos de reproducción, distribución, transformación y comunicación pública en todas sus posibles modalidades, con expresa facultad de cesión a terceros y con la duración máxima prevista en la Ley de Propiedad Intelectual. Cuando un usuario envía contenidos a elDiaro.es declara, garantiza y acepta que tiene derecho a hacerlo libremente, que esa información no infringe ningún derecho de propiedad intelectual, marca, patente o secreto comercial, que ese contenido no tiene carácter confidencial y que no es perjudicial para terceros. De igual modo, elDiaro.es aclara que podrá utilizar en la confección de sus informaciones contenidos creados por los usuarios licenciados en Creative Commons.

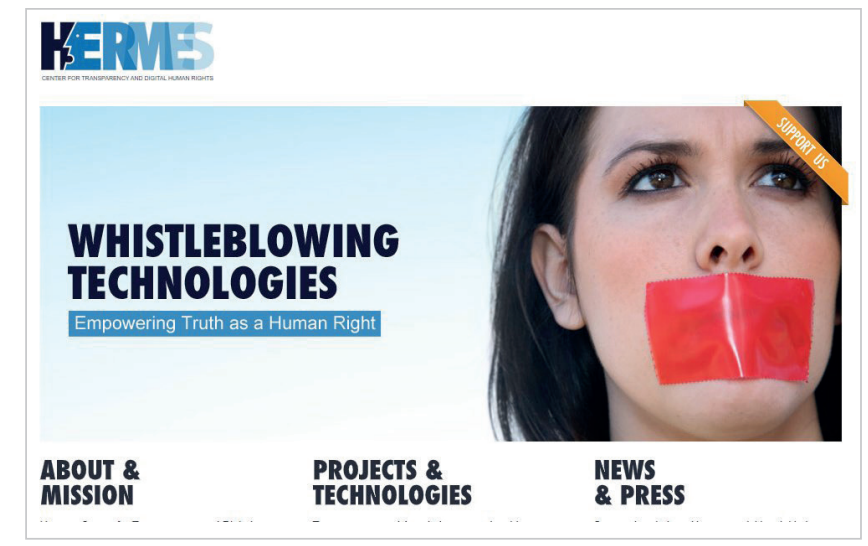

https://www.hermescenter.org 
Ligado también a la creación o cocreación de contenidos, pero en este caso a partir de los materiales publicados por el diario, el medio emplea la licencia BY-SA, la más abierta de todas las Creative Commons. Esto significa que cualquier usuario puede copiar, difundir o remezclar en internet contenido extraído del digital, incluso con ánimo de lucro, siempre que ese usuario también emplee ese tipo de licencia (CC-BY-SA) y que cite y enlace la fuente y la autoría del contenido utilizado, excepto cuando esos materiales proceden de terceros o son atribuibles a agencias de información o a cualquier otra empresa diferente [los dibujos de las viñetas no pueden reproducirse con fines comerciales (CC-BY-NC)]. Se aprecia, por tanto, una apuesta firme por la cocreación en espacios ajenos al medio, como pueden ser los blogs y las webs personales o las redes sociales, con la finalidad de aumentar el retorno en forma de comunidad y beneficio indirecto.

\subsection{Mediapart (Francia)}

Mediapart se autodefine como un periódico digital independiente y participativo. Fundado en 2008 por cuatro periodistas de prensa tradicional, sus creadores y otros dos socios poseen actualmente el $60 \%$ del capital. Se fundamenta en un modelo de pago, exento de publicidad y sustentado por las aportaciones de los socios, por lo que no se permite la visualización de contenidos a los lectores que no están abonados.

El periódico ofrece a sus suscriptores un espacio de expresión pluralista pensado especialmente para la cocreación de contenidos. En ese espacio, denominado Club, los socios pueden aportar contribuciones personales, editar y publicar textos, enlaces, imágenes, vídeos y grabaciones de sonido. Todas las participaciones son de acceso libre para el resto de usuarios, con independencia de que sean suscriptores o no, a diferencia de lo que sucede en las derivadas de los contenidos para abonados, que solo ellos pueden visualizar y viralizar.

A cada suscriptor se le proporciona la posibilidad de abrir un blog y de reaccionar activamente a las publicaciones de los demás, de modo que se pretende crear un entorno participativo semejante a una red social. A ello se añaden otras funciones como seguir en tiempo real las aportaciones de los colaboradores del Club, recibir diariamente una selección de las entradas más relevantes sobre un tema determinado e imprimir el periódico en formato pdf. No es necesario estar suscrito para descargar la app, aunque sí para acceder a los contenidos, excepto a los cocreados por los usuarios en el espacio participativo.

La intervención en el medio no se restringe a la aportación de contenidos y al diálogo social entre usuarios, sino también al envío por parte de los lectores de datos que puedan complementar esas contribuciones. Las aportaciones comunitarias son responsabilidad exclusiva de sus autores y no se someten a ningún tipo de control editorial previo salvo en los casos en que se informe al medio de que se están infringiendo las normas de la comunidad. Esto significa, pues, que la moderación siempre se realiza ex post facto en una apuesta decidida por la libertad de expresión, a pesar de que se permite la participación con nick siempre que el pseudónimo sea estable en el tiempo y no cree confusión de identidad con otra persona física o jurídica. El medio se reserva el derecho de

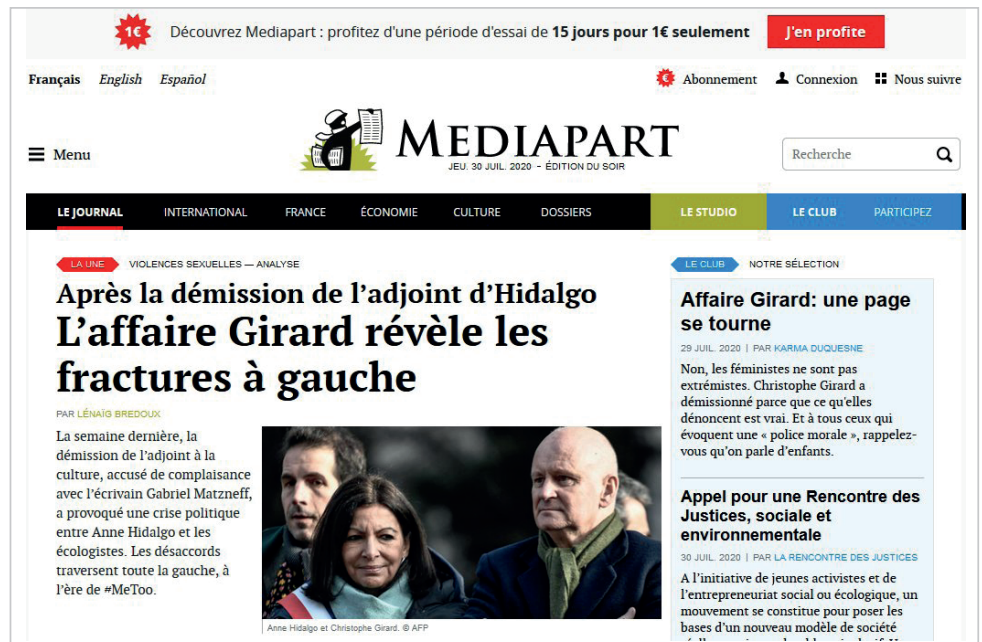

https://www.mediapart.fr recomendar cualquier comentario o participación de un usuario tras su publicación y también puede modificar el título y la presentación si considera que así el producto adquiere un valor mayor.

Mediapart exige a los usuarios que se cercioren acerca de los derechos de propiedad intelectual para poder reproducir o difundir contenidos cocreados y se exime de cualquier responsabilidad al respecto. En el supuesto de que un autor autorizase la reproducción de una creación y luego retirase esa concesión, el contenido cocreado también debe retirarse. Una vez publicados los contenidos los cocreadores aceptan que Mediapart pueda reproducirlos en cualquier soporte. En cambio, los intercambios privados que se producen entre los suscriptores y el equipo editorial no pueden difundirse sin el consentimiento de los participantes.

La compañía editora otorga al usuario los derechos de reproducción del contenido de la web en una sola pantalla y de almacenaje de un ejemplar como copia de seguridad o para impresión en papel. Se trata, pues, de un derecho de uso personal y privado, que no contempla la difusión ni de manera colectiva ni a terceros. De igual modo, se prohíbe la reproducción y el uso del logotipo y de la marca comercial, así como modificar, copiar, traducir, reproducir, vender, publicar, explotar y difundir todo tipo contenido textual o audiovisual presente en la página corporativa.

En las cocreaciones no se permite ningún tipo de remuneración y se exige un cumplimiento estricto de las normas de participación. Si un usuario las quebranta de manera comprobada y reiterada se le puede privar de sus derechos de 
participación durante un periodo de una semana, que puede aumentar a un mes, luego a seis e, incluso, derivar en la exclusión definitiva. La eliminación de participaciones ofensivas o que violen las normas se extiende igualmente a los motores de búsqueda externos al medio.

A pesar de no estar suscritos, los usuarios pueden hacer propuestas de temas, enviar testimonios o contenidos a Mediapart mediante un formulario de contacto. El periódico también ha habilitado la aplicación FrenchLeaks, que permite a las fuentes la transmisión segura y confidencial de documentos que puedan resultar de interés público y que, por otra parte, proporciona a los usuarios el acceso gratuito a documentos que han sido investigados por periodistas del medio.

\subsection{Observador (Portugal)}

Los usuarios sin registrar pueden acceder a todos los contenidos, con excepción de a determinados artículos denominados Premium, aquellos que el medio considera informaciones exclusivas que la competencia no posee. También tienen la opción de proponer una corrección del texto o de enviar algún contenido que pueda complementar la información. Para ello se facilita el correo electrónico del periodista que elabora el texto, aunque no se habilitan otros canales más directos e instantáneos como podría ser WhatsApp. La web indica claramente que tanto los mensajes como los contenidos publicados por los usuarios podrán utilizarse con finalidad editorial o informativa, de tal modo que el usuario cede sus derechos de autor en el momento que participa en cualquier espacio habilitado por la comunidad de Observador.

Es necesario registrarse para configurar el temario a la carta mediante un sistema de alertas disponible tanto en la app como en la web, para generar una lista de informaciones guardadas que pueden leerse más tarde -incluso offline- y para acceder a un histórico de contenidos ya visitados. Para realizar comentarios, votar o participar en la comunidad social también se exige registro, ya sea mediante email o redes sociales. Sin embargo, a diferencia de lo que sucede en elDiaro.es y en Mediapart, el perfil del comentarista es público y no se permite la utilización de nicks. La filosofía del medio apuesta por construir un espacio participativo vibrante y transparente, pero se reserva la posibilidad de intervenir en la participación de los miembros de la comunidad, pudiendo destacar, eliminar o premiar cualquier tipo de aportación. Esto significa que las contribuciones pasan primero por un sistema de

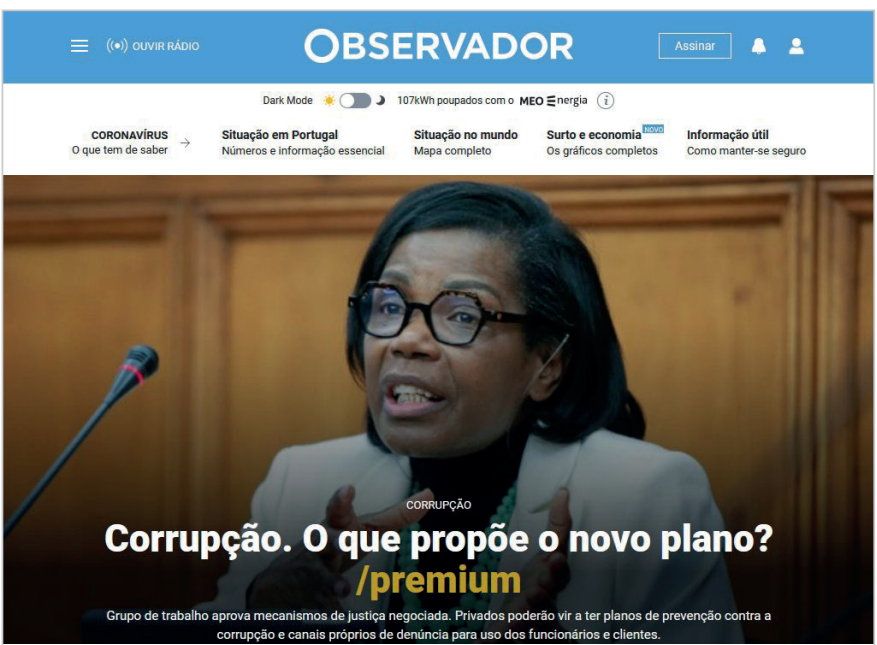

https://observador.pt puntuación automática y a continuación las evalúa el equipo de moderación del periódico con la finalidad de garantizar, aseguran, que sólo se publiquen participaciones constructivas y relevantes. Este sistema de puntuación automática registra el histórico de aportaciones anteriores del lector y, a pesar de que trabajan para reducir los tiempos de aprobación por parte del medio, todos los comentarios nuevos deben pasar este filtro para evitar la creación de cuentas falsas, anónimas o duplicidades desde cuentas diferentes.

Las posibilidades de cocrear se reducen para todos aquellos usuarios que escriban comentarios que no superen los filtros de los editores y, como es lógico, para los que reciban denuncias confirmadas o los que realicen denuncias que no sean válidas o pertinentes. Como sucede en todos los cibermedios estudiados, las empresas se reservan el derecho de eliminar registros falsos o que presenten una apariencia dudosa, así como todos aquellos que sean irrespetuosos $u$ ofensivos con cualquier miembro de la comunidad.

Los socios poseen acceso ilimitado a todo el contenido, se les envía una newsletter con historias y curiosidades que atingen al desarrollo interno de la redacción y están menos expuestos a la publicidad intrusiva de las páginas. En consecuencia, Observador anima a asociarse a todos los lectores que les ayuden a interpretar la información que producen, a los que valoren de forma especial sus reportajes, análisis, opiniones, fact checks y a los que, en definitiva, contribuyan a garantizar su independencia periodística.

El estatuto editorial del medio pone de manifiesto el propósito de situarse a la cabeza de los cambios tecnológicos y relacionales, así como su intención de promover políticas de innovación e incentivar la interacción con los lectores. Contrariamente a lo que sucede en elDiaro.es, Observador expone que todos los contenidos que figuran en sus espacios digitales son propiedad exclusiva del medio y, en consecuencia, están protegidos por los derechos de autor y de propiedad intelectual que estipulan las legislaciones portuguesa y europea, por lo que no pueden ser utilizados sin consentimiento expreso.

\subsection{Politico (Estados Unidos)}

Politico, el nativo digital que ha revolucionado la información política en Estados Unidos y que pretende ser la fuente política de referencia en el mundo, sigue siendo totalmente gratuito, aunque ya ofrece una versión de pago, Politico Pro, que cuenta con más de 28.000 suscriptores. Su misión siempre ha consistido en conseguir audiencia proporcionán- 
dole información precisa, imparcial e impactante y ofreciéndole productos altamente innovadores que aporten valor al usuario. Desde 2015 Politico cuenta con una edición europea, aunque en este caso analizamos la versión americana.

https://www.politico.eu

Los usuarios no registrados pueden acceder a la totalidad del contenido de la versión gratuita y están habilitados para dialogar en la comunidad mediante comentarios que exigen visualización pública del perfil de Facebook. También está disponible una versión digital que reproduce la edición impresa, pero que incluye opciones multimedia que permiten examinar el contenido mediante búsquedas, compartirlo en redes sociales o emplear navegación táctil.

Los registrados a través de email se suscriben automáticamente a un boletín de noticias y, si lo desean, pueden recibir la versión electrónica del periódico impreso en el correo. La edición de pago, Politico Pro, está orientada a periodistas especializados en información política y no al usuario final. Actúa como un proveedor de datos en que los suscriptores tienen acceso a noticias exclusivas, se les permite la personalización de las alertas, reciben noticias vespertinas, se les invita a eventos en que participan los profesionales del medio y se les brinda la oportunidad de formular preguntas al equipo de editores y periodistas de Pro. Aparte de la app en abierto, existe también una versión específica para Pro que permite personalizar los contenidos y facilita un directorio interactivo de Capitol Hill (el barrio residencial de Washington donde está el Capitolio y otras instituciones del Gobierno).

Las opciones de cocreación en Politico son, por tanto, limitadas para el público generalista, mientras que para el especializado se enfocan como una base de datos personalizados que permite a los profesionales crear historias de valor en otros medios o sitios web.

Tabla 3. Resumen de las posibilidades de participación para usuarios

\begin{tabular}{|c|c|c|c|c|c|c|c|c|}
\hline $\begin{array}{l}\text { Medio } \\
\text { (año de } \\
\text { creación) }\end{array}$ & Public. & App & Usuarios sin registrar & Usuarios registrados & Nick & Socios & $\begin{array}{l}\text { Derechos au- } \\
\text { tor del user } \\
\text { generated } \\
\text { content }\end{array}$ & $\begin{array}{l}\text { Derechos } \\
\text { autor } \\
\text { medio }\end{array}$ \\
\hline $\begin{array}{l}\text { De } \\
\text { correspondent } \\
(2013)\end{array}$ & No & No & $\begin{array}{l}\text { Sin acceso a conte- } \\
\text { nidos }\end{array}$ & $\begin{array}{l}\text { Propuestas de cocrea- } \\
\text { ción de contenidos }\end{array}$ & No & $\begin{array}{l}\text { - } \text { Colaboración con } \\
\text { socios expertos en } \\
\text { temas } \\
\text { - Involucración en } \\
\text { investigaciones } \\
\text { - } \text { Lectores como fuen- } \\
\text { te de valor }\end{array}$ & Autor & Medio \\
\hline $\begin{array}{l}\text { elDiario.es } \\
(2012)\end{array}$ & Sí & Sí & $\begin{array}{l}\text { - Acceso total a con- } \\
\text { tenidos } \\
\text { - Filtraciones confi- } \\
\text { denciales }\end{array}$ & $\begin{array}{l}\text { - Corrección de } \\
\text { textos } \\
\text { - Interacciones } \\
\text { sociales } \\
\text { - Personalización } \\
\text { temas en app }\end{array}$ & Sí & $\begin{array}{l}\text { - Comentarios tenidos } \\
\text { en cuenta por la } \\
\text { redacción } \\
\text { - Encuentros específicos } \\
\text { - Votaciones online }\end{array}$ & Medio & $\begin{array}{l}\text { Usuario } \\
\text { (CC-BY-SA) }\end{array}$ \\
\hline $\begin{array}{l}\text { Mediapart } \\
(2008)\end{array}$ & No & Sí & $\begin{array}{l}\text { - Sin acceso a conteni- } \\
\text { dos (sólo cocreados) } \\
\text { - Propuestas de temas } \\
\text { y ugc } \\
\text { - Filtraciones confi- } \\
\text { denciales }\end{array}$ & - & Sí & $\begin{array}{l}\text { - Club para la cocreación } \\
\text { - Blog y espacio parti- } \\
\text { cipativo }\end{array}$ & Medio & Medio \\
\hline $\begin{array}{l}\text { Observador } \\
(2014)\end{array}$ & Sí & Sí & $\begin{array}{l}\text { - Acceso parcial a } \\
\text { contenidos } \\
\text { - Corrección de textos } \\
\text { - Envío de ugc }\end{array}$ & $\begin{array}{l}\text { - Interacciones } \\
\text { sociales } \\
\text { - Alertas } \\
\text { - Temario personali- } \\
\text { zado en app }\end{array}$ & No & $\begin{array}{l}\text { Se añade acceso y } \\
\text { participación en conte- } \\
\text { nidos Premium }\end{array}$ & Medio & Medio \\
\hline $\begin{array}{l}\text { Politico } \\
(2006)\end{array}$ & Sí & Sí & $\begin{array}{l}\text { - Acceso total a conte- } \\
\text { nidos gratuitos } \\
\text { - Interacciones } \\
\text { sociales }\end{array}$ & - & - & $\begin{array}{l}\text { - Acceso total a conte- } \\
\text { nidos Pro } \\
\text { - Periodistas especia- } \\
\text { lizados: } \\
\text { a) Proveedor de datos y } \\
\text { fuentes } \\
\text { b) Directorios interac- } \\
\text { tivos }\end{array}$ & - & Medio \\
\hline
\end{tabular}




\section{Resultados, grados de utilidad}

En relación con el objetivo principal que motiva esta investigación, hallamos que todos los diarios nativos digitales analizados presentan alguna fórmula que permite la cocreación de contenidos por parte de los usuarios. Los espacios participativos más desarrollados (objetivo 1) se encuentran en Mediapart y en De correspondent, los únicos medios que no albergan publicidad y limitan la participación a los socios. Esto provoca que no podamos referirnos a una implantación plena de los procesos cocreativos, puesto que se condiciona el empoderamiento ciudadano al pago de una cuota de suscripción.

Se diagnostican tres tipos de acceso a la información en función del nivel de compromiso del usuario con el medio (objetivo 2): (1) lectores sin registrar, (2) usuarios registrados y (3) asociados. Son precisamente los medios que patentan un mayor grado de implantación de cocreación los que no permiten el acceso en abierto a los contenidos o exigen datos personales para el envío de propuestas o ugc. En los medios cuyo modelo de negocio se sustenta en ingresos por publicidad más suscripciones, los contenidos se ofrecen en abierto (elDiario.es), parcialmente en abierto (Observador) o en abierto, pero con una versión diferente para abonados (Politico).

Esta limitación al contenido obstaculiza el acceso a las fórmulas de cocreación más sencillas y consolidadas como la participación en las comunidades sociales (objetivo 3). Como no se puede comentar lo que no se puede leer, la colaboración ciudadana se restringe al envío de propuestas de temas, ugc o filtraciones confidenciales al equipo editorial como sucede en Mediapart. En cambio, los medios con contenidos en abierto exigen datos personales (registro de usuario) para corregir textos (elDiario.es), interactuar o personalizar la app (elDiario.es y Observador), de modo que los datos se convierten en un elemento de valor para la conversión de registrados en abonados, aunque Mediapart y elDiario.es permitan el empleo de nicks en el registro. Salvo en el caso de Observador las comunidades sociales funcionan de manera totalmente autónoma y no existe revisión previa de las aportaciones. De correspondent es el único medio que no cuenta con app, aunque en el resto de medios no se aprecian diferencias significativas entre las opciones ofrecidas en la web y en la aplicación más allá de la personalización de temarios que permiten medios como Observador y elDiario.es.

Mediapart es el único diario que presenta un sitio específico para la cocreación. En relación con el objetivo 4 referente a la evaluación de la arquitectura web, se aprecia que se trata de un espacio fácilmente accesible para el usuario, exige abono para crear a pesar de que se ofrece en acceso abierto para lectura y los ugc pasan a ser propiedad del medio. De correspondent no cuenta con un espacio delimitado en su web y la accesibilidad a las opciones de cocreación es compleja, pero considera a los lectores como fuente de valor, los implica en las investigaciones y en los trabajos periodísticos, y mantiene los derechos de autor para el creador. En elDiario.es el grado de implantación de la cocreación disminuye, a pesar de que las aportaciones de los socios son tenidas en cuenta por la redacción y se crean para ellos actividades que implican integración en el medio, mientras que en Observador la cocreación se limita a las aportaciones sociales en las comunidades de usuarios, lo que implica la explotación de espacios externos más que de la web corporativa, una tendencia que también se reproduce en Politico, pero en este caso orientada al periodismo de datos y a la especialización política.

En la tabla 4 se califica el grado de utilidad alcanzado por los nativos digitales en función de cada objetivo planteado en la investigación. Sólo Mediapart obtiene un grado alto, que podría ser total si el empoderamiento ciudadano no estuviese sometido a una cuota de suscripción. De correspondent y elDiario.es consiguen el grado medio, en parte por la complejidad de la jerarquía web para acceder a los espacios de cocreación. Observador y Politico presentan todavía fórmulas incipientes vinculadas a la participación social en piezas elaboradas por el propio medio. En el caso de Observador se aplica un índice de corrección -2 por participación activa del equipo editorial en la moderación de la comunidad social:

Tabla 4. Puntuaciones alcanzadas por los medios nativos digitales

\begin{tabular}{|c|c|c|c|c|c|c|}
\hline & $\begin{array}{l}\text { Fórmulas } \\
\text { cocreación }\end{array}$ & $\begin{array}{c}\text { Empoderamiento } \\
\text { usuarios }\end{array}$ & $\begin{array}{l}\text { Acceso productos } \\
\text { cocreados }\end{array}$ & $\begin{array}{c}\text { Accesibilidad } \\
\text { web a la } \\
\text { cocreación }\end{array}$ & $\begin{array}{c}\text { Puntuación } \\
\text { (hasta } 30 \text { puntos) }\end{array}$ & $\begin{array}{c}\text { Grado de } \\
\text { implantación } \\
\text { de la cocreación }\end{array}$ \\
\hline De correspondent & $B+C$ & B & C & $\mathrm{E}$ & 15 & Medio \\
\hline elDiario.es & $C+D+E$ & $\mathrm{~B}$ & A & $\mathrm{C}$ & 18 & Medio \\
\hline Mediapart & $A+B$ & $C$ & A & A & 22 & Alto \\
\hline Observador & $\mathrm{C}+\mathrm{E}$ & $\mathrm{B}(-2)$ & $A$ & $\mathrm{D}$ & 13 & Bajo \\
\hline Politico & $\mathrm{E}$ & C & A & $A$ & 14 & Bajo \\
\hline
\end{tabular}

\section{Discusión y conclusiones}

Los diarios nativos digitales apuestan por la cocreación de contenidos como un elemento que incrementa el pluralismo informativo y, por tanto, el valor del medio. En la línea de lo descrito por Kotler (2018), la integración de los públicos en la confección de los productos es una tendencia generalizada en todo tipo de empresas y organizaciones y descubrimos 
que los periódicos nativos digitales no permanecen ajenos a esta práctica innovadora. La aportación del valor procede en su caso de tres factores sólidos:

- la personalización de las experiencias de consumo,

- la habilitación de espacios para la creación de contenidos,

- las contribuciones interactivas y dialógicas en las comunidades sociales.

Se confirman, asimismo, los hallazgos de los estudios de Prahalad y Ramaswamy (2004) o Aitamurto (2013) en el sentido de que los medios más comprometidos con la cocreación ofrecen espacios que involucran al lector de manera personalizada.

Sin embargo, en el caso concreto de la cocreación el grado de utilidad alcanzado por los periódicos nativos digitales no son tan elevados como pudiera pensarse a priori. Sólo Mediapart ha desarrollado un espacio concebido exclusivamente para este cometido, aunque se localizan otras iniciativas valiosas como la integración de los públicos en las investigaciones periodísticas -por ejemplo, en De correspondent- o la habilitación de plataformas para la filtración de documentos que garantizan la confidencialidad y el anonimato de las fuentes como filtrala.org de elDiario.es o FrenchLeaks de Mediapart. Con todo, a pesar de la existencia de estos espacios abiertos a la colaboración, la utilidad mengua debido a dos circunstancias: un grado bajo de empoderamiento ciudadano motivado por la exigencia de registro o cuota de suscripción para acceder a los lugares pensados para la cocreación y, en segundo lugar, una arquitectura web que resulta compleja para localizar estos espacios.

De acuerdo con los estudios de Piller, Ihl y Vossen (2010) no estaríamos hablando, pues, de un empoderamiento total de los públicos para aceptar el proceso de cocreación sin limitaciones, sino de un empoderamiento creativo supeditado a la decisión final del medio y a la aceptación de sus condiciones de registro y asociación, en especial en aquellos casos cuya financiación no contempla la inserción publicitaria para mantenerse fieles a las misiones empresariales que apuestan por un periodismo libre e independiente de presiones políticas y económicas. De todas formas, el empoderamiento total sin intervención editorial entendemos que es difícilmente comprensible en los medios de comunicación, a quienes las sociedades democráticas les exigen garantías de fiabilidad y servicio público.

Ningún medio cuestiona el valor de los productos cocreados, filtrados o facilitados por los usuarios y todos coinciden en que satisfarán las necesidades de quienes los proporcionan y de la audiencia en general, aunque sólo De correspondent remunera las colaboraciones. Como apuntaron Segarra-Saavedra y Tur-Viñes (2017), al aumentar la satisfacción crecen las posibilidades de que los consumidores se conviertan en adprosumers, si bien las probabilidades aumentarían exponencialmente si tanto el acceso a los espacios para cocrear como a los productos cocreados fuesen totalmente en abierto, lo que también mejoraría los índices de impacto en las comunidades sociales. Atendiendo al modelo DART (diálogo, acceso, riesgo, transparencia), deberían mejorarse el diálogo y el acceso, pero los riesgos y la transparencia están bien especificados, aunque son difícilmente accesibles a pesar de su alta importancia, pues De correspondent es el único medio que mantiene los derechos de autor para los cocreadores.

Se diagnostica en todos los casos un aprovechamiento del conocimiento de los públicos (Sawhney; Prandelli, 2000) que repercute, en función del marco de referencia propuesto por Malmelin y Villi (2015), en la producción y en el marketing, pero no en el desarrollo, pues los medios ofrecen a los cocreadores los espacios que han pensado para ellos y les permiten promoción y distribución de los productos en los entornos sociales, pero no se localiza ningún ejemplo de retroalimentación para la ideación o la renovación de prácticas, propuestas o iniciativas para la cocreación.

Los cibermedios nativos digitales deben seguir mejorando en la concepción de fórmulas para la cocreación de contenidos para equiparse con otras empresas no informativas que conciben este tipo de actuaciones como uno de los elementos que más valor les confiere y más satisface a sus consumidores. Uno de los grandes retos a los que se enfrentan es hacer entender a los cocreadores que su valor reside en el papel de fuentes, pero que no son periodistas, por lo que debería aumentarse su implicación en las investigaciones, mientras que los ugc deberían usarse para reforzar y complementar los trabajos periodísticos, no para sustituirlos. A los públicos también se les debería informar claramente de qué trabajos son cocreados y cuáles puramente periodísticos.
Uno de los grandes retos a los que se enfrentan los medios es hacer entender a los cocreadores que su valor reside en el papel de fuentes, pero que no son periodistas 


\section{Referencias}

Aalberg, Toril; Blekesaune, Arild; Elvestad, Eiri (2013). "Media choice and informed democracy: Toward increasing news consumption gaps in Europe?". The international journal of press/politics, v. 18, n. 3, pp. 281-303.

https://doi.org/10.1177/1940161213485990

Agrawal, Amit-Kumar; Kaushik, Arun-Kumar; Rahman, Zillur (2015). "Co-creation of social value through integration of stakeholders". Procedia, social and behavioral sciences, v. 189, pp. 442-448.

https://doi.org/10.1016/j.sbspro.2015.03.198

Ahn, Dae-Yong; Duan, Jason A.; Mela, Carl F. (2016). “Managing user-generated content: A dynamic rational expectations equilibrium approach". Marketing science, v. 35, n. 2, pp. 201-340.

https://doi.org/10.1287/mksc.2015.0937

Aitamurto, Tanja (2013). "Balancing between open and closed: Co-creation in magazine journalism”. Digital journalism, v. 1 n. 2, pp. 229-251.

https://doi.org/10.1080/21670811.2012.750150

Anderson, Chris (2013). "Towards a sociology of computational and algorithmic journalism". New media \& society, v. 15, n. 7, pp. 1005-1021.

https://doi.org/10.1177/1461444812465137

Aylen, Jonathan (2010). "Open versus closed innovation: Development of the wide strip mill for steel in the United States during the $1920 \mathrm{~s}$ ". $R$ \& D management, v. 40, n. 1, pp. 67-80.

https://doi.org/10.1111/j.1467-9310.2009.00576.x

Bakker, Piet (2012). "Aggregation, content farms and Huffinization: The rise of low-pay and no-pay journalism". Journalism practice, v. 6, n. 5-6, pp. 627-637.

https://doi.org/10.1080/17512786.2012.667266

Bendapudi, Neeli; Leone, Robert (2003). "Psychological implications of customer participation co-production". Journal of marketing, v. 67, n. 1, pp. 14-28.

https://doi.org/10.1509/jmkg.67.1.14.18592

Brodie, Roderick J.; Hollebeek, Linda D.; Jurić, Biljana; Ilić, Ana (2011). "Customer engagement: Conceptual domain, fundamental propositions and implications for research". Journal of service research, v. 14, n. 3, pp. $252-271$.

https://doi.org/10.1177/1094670511411703

Bruns, Axel (2010). “News produsage in a pro-am mediasphere: Why citizen journalism matters”. In: Meikle, Graham; Redden, Guy. News online: Transformations and continuities. Reino Unido: Palgrave Macmillan, pp. 132-147. ISBN: 978 0230233447

Bruns, Axel (2012). “Reconciling community and commerce?”. Information, communication \& society, v.15, n. 6, pp. 815-835.

https://doi.org/10.1080/1369118X.2012.680482

Bruns, Axel (2016). "Big data analysis". In: Witschge, Tamara; Anderson, Chris W.; Domingo, David; Hermida, Alfred. The SAGE hand book of digital journalism. Londres: SAGE, pp. 509-527. ISBN: 9781473906532

https://doi.org/10.4135/9781473957909

Cano, Elena (2015). "Las rúbricas como instrumento de evaluación de competencias en educación superior: ¿uso o abuso?". Profesorado. Revista de currículum y formación de profesorado, v. 19, n. 2, pp. 265-280.

Carpentier, Nico (2011). Media and participation: A site of ideological-democratic struggle. Chicago: Intellect, The University of Chicago Press. ISBN 9781841504070

https://oapen.org/search?identifier $=606390$

Carvalho, Carla-Sofia (2014). Value co-creation through online communities in the context of new social media sites. Dissertation submitted to Faculdade de Engenharia da Universidade do Porto to obtain the doctoral degree in Industrial Engineering and Management.

https://repositorio-aberto.up.pt/bitstream/10216/84717/2/27475.pdf

Castells, Manuel (1996). The rise of the network society. The information age: economy, society and cultura. Volumen I. Cambridge, Massachusetts: Blackwell Publishers. ISBN: 9781405196864

Chadwick, Andrew (2013). The hybrid media system: Politics and power. Oxford: Oxford University Press. ISBN: 978 0199759477

Chesbrough, Henry William (2006). "New puzzles and new findings". In: Chesbrough, Henry William; Vanhaverbeke, Wim; West, Joel. Open innovation: Researching a new paradigm, Oxford: Oxford University Press, pp. 15-34. ISBN: 978 0199290727 
Comor, Edward (2010). "Digital prosumption and alienation". Ephemera. Theory \& politics in organization, v. 10, n. 3/4, pp. 439-454.

http://www.ephemerajournal.org/sites/default/files/10-3comor.pdf

De-la-Peña, Nonny; Weil, Peggy; Llobera, Joan; Giannopoulos, Elias; Pomés, Ausiàs; Spanlang, Bernhard; Friedman, Doron; Sánchez-Vives, María V.; Slater, Mel (2010). "Immersive journalism: Immersive virtual reality for the first-person experience of news". Presence, v. 19, n. 4, pp. 291-301.

https://doi.org/10.1162/PRES_a_00005

Deuze, Mark (2004). "What is multimedia journalism?”. Journalim studies, v. 5, n. 2, pp. 139-152. https://doi.org/10.1080/1461670042000211131

Fiore, Ann-Marie; Kim, Jihyun; Lee, Hyun-Hwa (2005). "Effect of image interactivity technology on consumer responses toward the online retailer". Journal of interactive marketing, v. 19, n. 3, pp. 38-53.

https://doi.org/10.1002/dir.20042

Firat, Fuat; Dholakia, Nikhilesh; Venkatesh, Alladi (1995). “Marketing in a postmodern world". European journal of marketing, v. 29, n. 1, pp. 40-56.

https://doi.org/10.1108/03090569510075334

Fournier, Susan; Avery, Jill (2011). "The uninvited brand". Business horizons, v. 54, n. 3, pp. 193-207. https://doi.org/10.1016/j.bushor.2011.01.001

Franklin, Bob (2014). “The future of journalism”. Digital journalism, v. 2, n. 3, pp. 254-272. https://doi.org/10.1080/21670811.2014.930253

Frow, Pennie; Nenonen, Suvi; Payne, Adrian; Storbacka, Kaj (2015). "Managing co-creation design: A strategic approach to innovation". British journal of management, v. 26, pp. 463-483.

https://doi.org/10.1111/1467-8551.12087

Fuente-Cobo, Carmen (2017). "Públicos vulnerables y empoderamiento digital: el reto de una sociedad e-inclusiva". El profesional de la información, v. 26, n. 1, pp. 5-12.

https://doi.org/10.3145/epi.2017.ene.01

George-Palilonis, Jennifer (2012). The multimedia journalis. Storytelling for today's media landscape. Oxford: Oxford University Press. ISBN: 9780199764525

Graham, Gary (2015). "Transforming the news value chain in the social era: A community perspective". Supply chain management, v. 20, n. 3, pp. 313-326.

https://doi.org/10.1108/SCM-05-2014-0147

Gruner, Kjell; Homburg, Christian (2000). “Does customer interaction enhance new product success?”. Journal of business research, v. 49, n. 1, pp. 1-14.

https://doi.org/10.1016/S0148-2963(99)00013-2

Guallar, Javier; Codina, Lluís (2018). "Journalistic content curation and news librarianship: differential characteristics and necessary convergence". El profesional de la información, v. 27, n. 4, pp. 778-790.

https://doi.org/10.3145/epi.2018.jul.07

Hartley, John (2004). "The new economy, creativity and consumption". International journal of cultural studies, v. 7, n. 1, pp. 5-7.

https://doi.org/10.117/1367877904040600

Hermida, Alfred (2011). "Fluid spaces, fluid journalism: the role of the 'active recipient' in participatory journalism”. In: Singer, Jane; Hermida, Alfred; Domingo, David; Heinonen, Ari; Paulussen, Steve; Quandt, Thorsten; Reich, Zvi; Vujnovic, Marina. Participatory journalism: Guarding open gates at online newspapers. Chichester: Wiley-Blackwell, pp. 177-191. ISBN: 9781444332261

https://doi.org/10.1002/9781444340747.ch10

Hollebeek, Linda (2013). "The customer engagement/value interface: An exploratory investigation". Australasian marketing journal (AMJ), v. 21, n. 1, pp. 17-24.

https://doi.org/10.1016/j.ausmj.2012.08.006

Holmes, Su (2004). "'But this time you choose!' Approaching the 'interactive audience in reality TV". International journal of cultural studies, v. 7, n. 2, pp. 213-231.

https://doi.org/10.1177/1367877904043238

Holton, Avery E.; Lewis, Seth C.; Coddington, Mark (2016). “Interacting with audiences”. Journalism studies, v. 17, n. 7, pp. 849-859.

https://doi.org/10.1080/1461670X.2016.1165139 
Ind, Nicholas; Coates, Nick (2013). "The meanings of co-creation”. European business review, v. 25, n. 1, pp. 86-95. https://doi.org/10.1108/09555341311287754

Jenkins, Henry; Carpentier, Nico (2013). Theorizing participatory intensities: A conversation about participation and politics". Convergence: The international journal of research into new media technologies, v. 19, n. 3, pp. $265-286$. https://doi.org/10.1177/1354856513482090

Kaplan, Andreas M.; Haenlein, Michael (2010). "Users of the world, unite! The challenges and opportunities of social media". Business horizons, v. 53, n. 1, pp. 59-68.

https://doi.org/10.1016/j.bushor.2009.09.003

Karlsson, Michael (2011). "Flourishing but restrained. The evolution of participatory journalism in Swedish online news, 2005-2009". Journalism practice, v. 5, n. 1, pp. 68-84.

https://doi.org/10.1080/17512786.2010.486605

Kim, Jae-Eun; Ju, Hae Won; Johnson, Kim (2009). “Sales associate's appearance: links to consumers' emotions, store image, and purchases". Journal of retailing and consumer science, v. 16, n. 5, pp. 407-413.

https://doi.org/10.1016/j.jretconser.2009.06.001

Kool, Hollis (2016). "The ethics of immersive journalism: A rhetorical analysis of news storytelling with virtual reality technology". Intersect, v. 9, n. 3, pp. 1-11.

http://ojs.stanford.edu/ojs/index.php/intersect/article/view/871

Kotler, Philip (1991). Marketing management. Analysis, planning, implementation and control. Englewood Cliffs, New Jersey: Prentice-Hall. ISBN: 9780137228515

Kotler, Philip (2002). Marketing management. Englewood Cliffs, New Jersey: Prentice Hall. ISBN: 9780130336293

Kotler, Philip (2018). Marketing 4.0: transforma tu estrategia para atraer al consumidor final. Madrid: LID Editorial Empresarial, S.L. ISBN: 9788417277826

Küng, Lucy (2016). Strategic management in the media. From theory to practice. University of Oxford: SAGE Publications Ltd. ISBN: 9781412903134

López-Roldán, Pedro; Fachelli, Sandra (2015). "El diseño de la muestra”. En: López-Roldán, Pedro; Fachelli, Sandra. Metodología de la investigación social cuantitativa. Bellaterra: Dipòsit Digital de Documents, Universitat Autònoma de Barcelona.

https://ddd.uab.cat/record/185163

Malmelin, Karoliina; Malmelin, Nando (2015). "Faith-based organizations and the challenges of public legitimation: A case for communications". International journal of public leadership, v. 11, n. 3/4, pp. 166-179. https://doi.org/10.1108/ IJPL-08-2015-0022

Malmelin, Nando; Villi, Mikko (2015). "Audience community as a strategic resource in media work. Emerging practices". Journalism practice, v. 10, n. 5, pp. 589-607.

https://doi.org/10.1080/17512786.2015.1036903

Malthouse, Edward; Hofacker, Charles (2010). "Looking back and looking forward with interactive marketing". Journal of interactive marketing, v. 24, n. 3, pp. 181-184.

https://doi.org/10.1016/j.intmar.2010.04.005

Mariën, Ilse; Prodnik, Jernej A. (2014) “Digital inclusión and user (dis)empowerment: A critical perspective". Info, v. 16, n. 6, pp. 35-47.

https://doi.org/10.1108/info-07-2014-0030

Masip, Pere; Suau, Jaume (2014). “Audiencias activas y modelos de participación en los medios de comunicación españoles". Hipertext.net, n. 12.

https://doi.org/10.2436/20.8050.01.3

Napoli, Philip M. (2010). "Revisiting 'mass communication' and the 'work' of the audience in the new media environment". Media, culture \& society, v. 32, n. 3, pp. 505-516.

https://doi.org/10.1177/0163443710361658

OHern, Matthew S.; Rindfleisch, Aric (2015). “Customer co-creation”. Review of marketing research, v. 6, pp. 84-106. https://doi.org/10.1108/S1548-6435(2009)0000006008

Örnebring, Henrik (2008). "The consumer as producer - of what? User-generated tabloid content in The Sun (UK) and Aftonbladet (Sweden)". Journalism studies, v. 9, n. 5, pp. 771-785.

https://doi.org/10.1080/14616700802207789 
Ostrom, Amy L.; Bitner, Mary-Jo; Brown, Stephen W.; Burkhard, Kevin A.; Goul, Michael; Smith-Daniels, Vicki; Demirkan, Haluk; Rabinovich, Elliot (2010). "Moving forward and making a difference: research priorities for the science of service". Journal of service research, v. 13, n. 1, pp. 4-36.

https://doi.org/10.1177/1094670509357611

Otzen, Tamara; Manterola, Carlos (2017). “Técnicas de muestreo sobre una población a estudio". International journal of morphology, v. 35, n. 1, pp. 227-232.

https://doi.org/10.4067/S0717-95022017000100037

Pavlíčková, Tereza; Kleut, Jelena (2016). “Produsage as experience and interpretation”. Participations. Journal of audience and reception studies, v. 13, n. 1, pp. 349-359.

https://bit.ly/2DmelyU

Picard, Robert (2014). "Twilight or new dawn of journalism: Evidence from the changing news ecosystem". Journalism studies, v. 15, n. 5, pp. 500-510.

https://doi.org/10.1080/1461670X.2014.895530

Picone, Ike (2011). "Produsage as a form of self-publication. A qualitative study of casual news produsage". New review of hypermedia and multimedia, v. 17, n. 1, pp. 99-120.

https://doi.org/10.1080/13614568.2011.552643

Piller, Frank T.; Ihl, Christoph; Vossen, Alexander (2011). "A typology of customer co-creation in the innovation process". In: Hanekop, Heidemarie; Wittke, Volker. New forms of collaborative production and innovation: Economic, social, legal and technical characteristics and conditions. Universität Göttingen, Deutschland, pp. 1-26. ISBN: 1445288048 https://doi.org/10.2139/ssrn.1732127

Porter, Michael (2004). Competitive strategy: Techniques for analyzing industries and competitors. New York: The Free Press. ISBN: 9780743260886

Potts, Jason; Hartley, John; Banks, John; Burgess, Jean; Cobcroft, Rachel; Cunningham, Stuart; Montgomery, Lucy (2008). "Consumer co-creation and situated creativity". Industry and innovation, v. 15, n. 5, pp. 459-474. https://doi.org/10.1080/13662710802373783

Prahalad, Coimbatore-Krishnarao; Ramaswamy, Venkat (2004). "Co-creation experiences: the next practice in value creation". Journal of interactive marketing, v. 18, n. 3, pp. 5-14.

https://doi.org/10.1002/dir.20015

Rampazzo, Renira; Peret, Lorena (2016). "Transmedia strategies in journalism. An analytical model for the news coverage of planned events". Journalism studies, v. 18, n. 11, pp. 1381-1399.

https://doi.org/10.1080/1461670X.2015.1127769

Real Academia Española (2005). Diccionario panhispánico de dudas.

https://www.rae.es/recursos/diccionarios/dpd

Roser, Thorsten; DeFillippi, Robert; Samson, Alain (2013). "Managing your co-creation mix: Co-creation ventures in distinctive contexts". European business review, v. 25, n. 1, pp. 20-41.

https://doi.org/10.1108/09555341311287727

Sánchez-Jiménez, Miguel-Ángel; Fernández-Allés, María-Teresa; Mier-Terán-Franco, Juan-José (2019). Relación entre los beneficios y la obtención de engagement de los usuarios en la comunicación de las redes sociales del sector hotelero. Revista de comunicación de la SEECI, n. 48, pp. 125-148.

http://doi.org/10.15198/seeci.2019.48.125-148

Sawhney, Mohanbir; Prandelli, Emanuela (2000). "Communities of practice: managing distributed innovation in turbulent markets". California management review, v. 42, n. 4, pp. 24-54.

https://cmr.berkeley.edu/search/articleDetail.aspx?article $=4475$

Scolari, Carlos-Alberto (2009). "Transmedia storytelling: Implicit consumers, Narrative worlds, and branding in contemporary media production". International journal of communication, v. 3, pp. 586-606.

http://ijoc.org/index.php/ijoc/article/view/477

Segarra-Saavedra, Jesús; Tur-Viñes, Victoria (2017). “Creatividad publicitaria: marcas vs. prosumer amateur. La viralidad del spot de Eugen Merher para Adidas". En: García-Medina, Irene; Tur-Viñes, Victoria. Diálogos bilaterales entre investigadores de la Glasgow Caledonian University (Reino Unido) y la Universidad de Alicante (España). Estudios interdisciplinares. Alicante: Universidad de Alicante: Colección Mundo digital de Revista mediterránea de comunicación, 10, pp. 175-184. ISBN: 9788461793884

https://doi.org/10.14198/MEDCOM/2017/10_cmd 
Shao, Guosong (2009). “Understanding the appeal of user-generated media: a uses and gratification perspective". Internet research, v. 19, n. 1, pp. 7-25.

https://doi.org/10.1108/10662240910927795

Singer, Jane (2005). "The political j-blogger: 'Normalizing' a new media form to fit old norms and practices". Journalism, v. 6, n. 2, pp. 173-198.

https://doi.org/10.1177/1464884905051009

Singer, Jane B.; Hermida, Alfred; Domingo, David; Heinonen, Ari; Paulussen, Steve; Quandt, Thorsten; Reich, Zvi; Vujnovic, Marina (2011). Participatory journalism: Guarding open gates at online newspapers. Malden, MA: Wiley-Blackwell. ISBN: 9781444332261 http://eu.wiley.com/WileyCDA/WileyTitle/productCd-1444332260.html

Soler-Campillo, María; Galán Cubillo, Esteban; Marzal-Felici, Javier (2019): “La creación de À Punt Mèdia (2013-19) como nuevo espacio público de comunicación". Revista latina de comunicación social, n. 74, pp. 1801-1817.

http://www.revistalatinacs.org/074paper/1411/94es.html

Sunstein, Cass (2017). \#Republic. Divided democracy in the age of social media. Hardcover Editions. ISBN: 9780691175515

Teece, David (2007). “Explicating dynamic capabilities: The nature and microfoundations of (sustainable) enterprise performance". Strategic management journal, v. 28, pp. 1319-1350.

https://doi.org/10.1002/smj.640

Thurman, Neil (2011): “Making 'The daily me': Technology, economics and habit in the mainstream assimilation of personalized news". Journalism: Theory, practice \& criticism, v. 12, n. 4, pp. 395-415. https://doi.org/10.1177/1464884910388228

Villi, Mikko (2012). "Social curation in audience communities: UDC (user-distributed content) in the networked media ecosystem". Participations: The international journal of audience and reception studies, v. 9, n. 2, pp. 614-632. http://www.cost-transforming-audiences.eu/node/1217

Wang, Liz C.; Baker, Julie; Wagner, Judy A.; Wakefield, Kirk (2007). "Can a retail web site be social?". Journal of marketing, v. 71, n. 3, pp. 143-157.

https://doi.org/10.1509/jmkg.71.3.143

Wardle, Claire; Williams, Andrew (2010). "Beyond user-generated content: a production study examining the ways in which ugc is used at the BBC". Media, culture \& society, v. 32, n. 5, pp. 781-799.

https://doi.org/10.1177/0163443710373953

Westlund, Oscar (2013). "Mobile news: A review and model of journalism in an age of mobile media". Digital journalism, v. 1 , n. 1, pp. 6-26. https://doi.org/10.1080/21670811.2012.740273

Wigley, Charles (2013). "Dispelling three myths about Likert scales in communication trait research". Communication research reports, v. 30, n. 4, pp. 366-372.

https://doi.org/10.1080/08824096.2013.836937

Yi, Youjae (1990). "A critical review of customer satisfaction". In: Zeithaml, Valarie. Review of marketing 1990. Chicago, IL: American Marketing Association, pp. 68-123. ISBN: 9789992962992

Yoo, Youngjin; Henfridsson, Ola; Lyytinen, Kalle (2010). "Research commentary - The new organizing logic of digital innovation: An agenda for information systems research". Information systems research, v. 21, n. 4, pp. 724-735. https://doi.org/10.1287/isre.1100.0322

Zhang, Kaifu; Sarvary, Miklos (2015). "Differentiation with user-generated content". Management science: Journal of the institute for operations research and the management sciences, v. 61, n. 4, pp. 898-914.

https://doi.org/10.1287/mnsc.2014.1907

\section{Bienvenido a $\Xi P$}

Revista cientifica internacional 